\title{
Public sensitivity to cultural identity and regime type of trading partners: a survey experiment from Turkey and Greece
}

\section{Osman Sabri Kiratli ${ }^{1}$}

Published online: 20 August 2020

(c) European Consortium for Political Research 2020

\begin{abstract}
Given that sharing a democratic regime or culture increases the likelihood of bilateral trade flows between country dyads, this article investigates whether individuals are more likely to support preferential trade liberalization with other democracies and countries they perceive as culturally similar to the home country. Adopting experimental manipulation of the regime type and the cultural identity of the partner country on nationally representative survey data from two emerging market countries, Turkey and Greece, I demonstrate that while cultural affiliation does not condition individual attitudes, respondents in both samples display a highly significant preference for trade liberalization with a democratic country over an authoritarian one. Assessments based on respondents' endorsement of postmaterialist values, international trade attitudes, and interpersonal trust reveal that while the democracy preference of Turkish respondents are likely affected by functional reasons, both functional and normative dynamics condition Greek attitudes.
\end{abstract}

Keywords Economic globalization · Emerging markets · FTAs $\cdot$ Public opinion · Survey experiments

\section{Introduction}

The unprecedented growth of international trade and greater transnational economic integration in the last three decades and the ensuing backlash in recent years have sparked considerable academic interest in the driving factors of individual

Electronic supplementary material The online version of this article (https://doi.org/10.1057/s4130 4-020-00290-x) contains supplementary material, which is available to authorized users.

Osman Sabri Kiratli

osmansabrikiratli@boun.edu.tr

1 International Trade Department, Bogazici University, Hisar Kampus Bebek, 34342 Istanbul, Turkey 
endorsement of trade liberalization. Studies have investigated the financial (e.g., Rodrik 1995), symbolic (e.g., Rankin 2001), ideational (e.g., Mayda and Rodrik 2005) and demographic (e.g., Scheve and Slaughter 2001) factors that shape trade preferences at the individual level.

Yet, two lines of criticisms derail the existing research. First, with certain notable exceptions (e.g., Baker 2003; Naoi and Urata 2013; Beaulieu et al. 2005), the majority of analyses focuses on public opinion in advanced Western economies, most notably the US. Second, in these studies, individual trade attitudes are either treated categorically, as respondents in the polls are questioned only on cases of universal trade liberalization, or support for specific cases of preferential trade agreementssuch as NAFTA — is equated with support for trade in general (e.g., Uslaner 1998; Ehrlich 2009; Granzin et al. 1997). However, individuals tend to develop diverging foreign policy opinions of other countries based on their perceived images (e.g., Kunczik 2016). Recent studies suggest that these images extend to play instrumental roles in driving attitudes on economic decisions ranging from FDI flows through foreign aid to investment decisions (Bush and Prather 2020; Jensen 2013; Steiner 2018; Jungherr et al. 2018; Kiratli 2020).

Though the recently populated literature provides substantial evidence for the argument that the public's evaluation of preferential trade agreements is closely affected by the choice of the partner, experimental analyses exploring the isolated effects of micro-level determinants of this association are rather limited. In one of the few such studies, Herrmann et al. (2001) find that on support for lifting trade barriers, Americans deliberate over whether the trade partner is an ally or enemy. In another notable example, through conjoint experiments embedded in national surveys in Costa Rica, Nicaragua and Vietnam, Spilker et al. demonstrate (2016) that respondents prefer culturally similar countries, democracies and countries with high environment and labor standards, yet do not provide details of the causal mechanisms that condition such preferences. Following this line of studies, in this article I focus on the regime type and the cultural affiliation of the trade partner. Through two experiments on nationally representative, independently conducted surveys in Turkey and Greece, I investigate if the preference for democratic and culturally similar trade partners holds in a different sample of countries, namely high-income emerging market economies. Moreover, this study moves beyond previous research by exploring which groups of individuals opt for democratic partners and why they do so.

Theoretically, I argue that two sets of dynamics may drive individual preference for democratic and culturally similar trade partners: Functionally, the institutional makeup of democratic regimes ensures greater economic and political stability and offers less uncertainty, better private property protection and higher product standards. Similarly, the shared political culture and social institutions embedded in specific cultural geographies would build up bilateral trust between the economic actors, boost communication and reduce the uncertainty and risk of business making. Normatively, both political regimes and cultural parity provide cues for individuals to define an in-group and an out-group. These heuristic derivatives would particularly be salient in trade issues where citizens lack access to informational tools to reach an informed judgment over the expected effects of preferential trade liberalization (e.g., Hicks et al. 2014; 
Naoi 2009). Given that people tend to display higher levels of concerns for the needs and interests of their own group members, for communities of states sharing similar sets of norms, values and beliefs, opening their respective economic borders will be evaluated not only based on the tangible benefits, but also as a normative good.

For the empirical analysis, I choose Turkey and Greece as significant cases, representing upper middle-income and high-income countries. According to the World Bank classification, these are the type of countries that, to date, studies on trade attitudes have neglected. Though they are under the strain of economic crises, both countries are economically open and well-integrated into global economic structures. Greece, as a member of the European Union, is a party to more than 40 free trade agreements (FTAs) in force and more than a dozen under negotiation. At the same time, the Greek financial crisis has long been considered a crucial test of European solidarity. Though not a member of the EU, Turkey is a strategic ally of the Union and has been a member of the Customs Union since 1996 as well as a party to more than 20 FTAs in force. Culturally, both Turkey and Greece are 'torn' countries driven by a perpetual tension to set the country's color between those who seek to affiliate with European cultural elements and those aspiring to more Eastern roots. Hence, they provide fertile grounds to assess the effect of competing cultures on attitudes while controlling for the cultural identity of respondents. Finally, these two neighbors differ significantly in the degree of democratic consolidation. According to the latest Freedom House data (2019), Greece has a democracy score of 88 , whereas Turkey scores only 32. This divergence in the diffusion of democratic values enables an independent assessment of the underlying dynamics of public preference for democratic trade partners moderated by the degree of democratic consolidation at home.

Based on the results of the survey experiments in which the regime type and the cultural proximity of the trade partner are manipulated in a hypothetical scenario, this article concludes that individuals in Turkey and Greece do not have a preference for trade partners that they consider belong to the same cultural group with the home country. Yet, voters in both countries are significantly more likely to consent to a free trade agreement with a democracy than an autocracy. The results suggest that there is substantially lower sensitivity to the democracy treatment in Turkey, arguably conditioned by a less advanced democratic political culture. Further subgroup analyses reveal that while the preference for democratic trade partners is uniformly distributed across different segments in Greece, in Turkey, those who hold materialist value orientation, are pro-free trade and have low interpersonal trust are significantly more favorable toward democratic partners. This finding indicates that even though both functional and normative dynamics condition Greek attitudes, the democracy preference of Turkish respondents seems incited solely by functional reasons.

\section{Theory}

Following previous works, the starting hypothesis of this study is that individual support for preferential trade liberalization will be stronger if the partner country is, first, a democracy and, second, perceived to be part of the same cultural group as the home country. 
The decision to problematize the regime type and cultural distance as instrumental factors in influencing trade attitudes is based on two premises: First, studies confirm that bilateral trade flows are considerably greater between democratic dyads (Dixon and Moon 1993) and dyads of culturally similar countries (e.g., Dow and Karunaratna 2006; Rauch 1999). Democracies also pursue less protectionism and sign more trade liberalization agreements with one another (e.g., Mansfield et al. 2000, 2002). Second, in democracies, public opinion influences trade policies (e.g., Mansfield et al. 2000; Kono 2008). As a result of regularly held competitive elections in democracies, vote-seeking politicians have an incentive to actively monitor public opinion and respond to their preferences, even on relatively low-salient foreign policy areas such as trade policies. If public opinion indeed affects trade policies, the higher frequency of preferential treatment we observe between democratic and culturally similar dyads should be conditioned—and justified—at the individual level. Thus, we might expect voters in trading countries to favor democracies and countries with lower cultural distance as trade partners.

The first set of factors that steer voter preference for democratic trade partners derive from functional benefits. The institutional framework inherent in democracies facilitates trade between private actors by reducing transaction costs, namely ex-ante and ex-post "costs of specifying and enforcing the contracts that underlie exchange" (North 1984: 7). Democracies have what Lipson calls "contracting advantages" based on the "reciprocal exchange of promises," thereby making agreements "less risky and more reliable in practice" (2005: 4). Transparency and openness in the institutional structure of democracies reduce the likelihood of uncertainties, leading to lower risk premiums (Russett 1994; Doyle 2005). In a business environment with less uncertainty, economic actors have to bear less of the information and monitoring costs. Moreover, once an agreement is reached, the rule of law and the protection of private property rights help actors overcome further ex-post costs to ensure future compliance. In autocracies, in contrast, the risks are always greater as the rules of the game can easily change. As the risks of conducting business grow, the cost of insurance increases and gains from trade decline. The institutional makeup of democracies, in short, contributes to stability and the continuity of business relations and consequently make democracies better trade partners.

Second, because democracies are more predisposed to sharing common political interests, bilateral problems are less likely to emerge or surge to the point of disrupting bilateral trade flows. Thus, private actors are able to conduct uninterrupted, stable economic relations with less risk of interference from outside actors in dealings with their partners (Bliss and Russett 1998: 1129). Differences in political interests in dyads with different political regimes, in contrast, may reduce consumer demand for each other's products and even mobilize citizens to boycott imports. Anti-apartheid boycotts against South African products by American consumers are a prominent example. A conflictual relation between two countries may also cause firms to switch their suppliers and markets to other states (Polachek 1980).

Third, the rule-of-law mechanisms also help to protect consumer rights, uphold production standards and enhance product safety (Rodrik 2000). The judicial checks and balances and strong democratic institutions increase economic actors' confidence in a foreign trade partner's importers and exporters (Barro 1999). 
Consequently, all other things being equal, products of democracies are overall of better quality and more reliable compared to non-democracies (Yu 2007), and importers trust the products of exporters with democratic regimes, particularly in institutionally dependent sectors, more (Levchenko 2007).

The second set of explanations is based on identities and normative preferences that may influence individual preferences, regardless of their exposure to international trade. Identities encompass sets of values and beliefs that act as 'mediating orientations' that closely affect the political behavior of individuals independent of what serves his or her best interests (Eckstein 2000). Some identities are more likely to condition certain behaviors. A communitarian identity with a restrictive understanding of what constitutes self-community would increase the saliency of ethnocentric, or even xenophobic, frames. Accordingly, others who belong to another community are more likely to be met with wariness as they carry the risk of threatening the integrity of one's culture. As such, in trade relations, a negative image of the target state and the out-group anxiety it inflicts may predispose an individual to oppose extending favorable trade agreements over fears of a loss of jobs and disintegration of cultural and social unity. A positive identification with the target state, conversely, will suppress ethnocentric views and spur support for trading freely with the country, as such transactions are not perceived as a threat to the economic, social and cultural way of life of the home country. Hence, individual attitudes toward a trade partner are colored by the way in which the partner is defined and categorized in relation to one's political community as an ideational construct.

Starting from Kant, the view that sharing a democratic regime leads to a common set of values, norms and worldviews has long been supported by normative explanations of democratic peace theories. Because citizens across democracies concur with each other in prioritizing a shared set of civic values, fundamental freedoms, human rights and liberal ideals, they are more likely to positively identify with each other and less likely to view the other as a threat. Once concerns of threat perception are allayed, trade proposals are evaluated based on calculations of absolute gains, rather than relative gains, and cooperation will be seen as more feasible.

Normative explanations of democratic peace theories emphasize organic ties, which are based on sharing a similar set of ideas on how to organize politics as the basis of a community. An alternative path of community formation that helps members define the insiders and outsiders is grounded on mechanical solidarity that is based on similarities between individuals. A core mechanism that fosters mechanical solidarity is culture. A cultural identity is a historical construct, with a relatively coherent set of norms, values and narratives commonly shared by its inhabitants (Katzenstein 2009). Members of the same cultural groups are socialized into similar sets of ideational constructs; they share collective understandings and common narratives and references. Functionally, such commonalities enhance communication, facilitate information sharing and minimize ambiguity between its members. Moreover, as a result of sharing a common set of identities, members of the same cultural groups are expected to view fellow individuals with greater mutual trust, benefit of the doubt and even solidarity. With trust, risk premiums decline and economic exchanges increase (Kaltenhaler and Miller 2013; Spilker et al. 2016). Normatively, proposals of trade liberalization with culturally similar countries are considered 
'appropriate' and evaluated positively merely on the grounds of ideational closeness and belonging to the greater whole. Conversely, preferential trade liberalization with countries from other cultural groups will be challenged as it will pose the danger of weakening the in-group and its way of life vis-à-vis the out-group, or the 'others' who hold a different composition of identities and follow dissimilar narratives and practices.

One should note an important distinction between the functional and normative mechanisms. Functional mechanisms shape attitudes by altering voters' expected utility from international trade. Thus, when voters evaluate the political regime of the partner country, functional reasons can be instrumental irrespective of the political regime type at home, if they believe that the institutional structure of democratic partners will serve their material interests. Normative dynamics, in contrast, derive from a shared sense of belonging and responsibility and thus are salient only if there are shared political and ideational commonalities with the partner country. In other words, the closer the perceived political or cultural distance between a partner country and home, the stronger the normative affiliation will be, hence the more supportive individuals would be of trade liberalization with that country. Thus, ceteris paribus, in consolidated democracies (Greece), individual sensitivity to democratic trade partners would be greater in degree as it will be driven by both functional and normative mechanisms than it is in weakly consolidated democracies (Turkey), where normative mechanisms will be much less salient than functional mechanisms.

If the relative potency of functional and normative mechanisms in fostering preferences might vary across countries, there should be observable differences in the way different groups of individuals approach trade liberalization with democracies. In particular, I argue that respondents' evaluation of democratic norms and values, general trade attitudes and interpersonal trust levels affect their susceptibility to the functional and normative factors.

Logically, if normative reasons do in fact condition positive trade attitudes toward other democracies, those with greater endorsement of democratic norms and values would be unequivocally supportive of preferential trade liberalization with other democracies and more sensitive to the democracy treatment. Conversely, if the driving mechanism is functional, whose benefits do not depend on the home country's democratic development nor personal belief in democratic values, we would anticipate a tenuous correlation between personal ideational predispositions toward democratic values and preference for democratic trade partner.

Crudely, the functionalist argument assumes that individuals prefer democratic trade partners because agreements with democracies net more profit than those with non-democracies. However, expectations of greater trade gains would only elicit support for democratic partners among those who actually support free trade. Those who do not, namely protectionists, in contrast, would place little value on the extra material benefits that trading with democratic partners will endow. In fact, those negatively affected by trade may even be resistant to trade liberalization with another democracy, considering that trade agreements with democracies will increase the volume of bilateral trade and thus inflict further damage on their financial situation. Theoretically, therefore, while the democracy preference for free trade is more likely to be moved by functional mechanisms, only perceived normative affiliations 
with other democracies may condition protectionists' support for democratic trade partners.

Generalized social trust leads economic actors to be more distrustful of 'foreigners' and perceive greater risks and uncertainty for themselves and their social groups (e.g., Whiteley 2000). As Uslaner (2003) concurs, people with lower levels of social trust are more risk averse and less inclined to evaluate economic transactions with strangers for mutual opportunities. Consequently, social trust is often positively correlated with pro-trade attitudes (e.g., Kaltenthaler and Miller 2013; Nguyen and Bernauer 2019). Moreover, when trust declines, actors intensify their efforts for monitoring and enforcement mechanisms, which in turn increases transaction costs and leads to efficiency losses (Putnam 1993). Thus, following the functionalist argument, those who are less trusting and more risk-averse have greater appreciation for the institutional and legal frameworks embedded in democratic trading partners and substantially lower risk premiums. Conversely, those with high levels of social trust are significantly less conditioned by the transactional advantages of trading with a democracy.

\section{Research design}

The data in this study were collected using face-to-face interviews with nationally representative sample of adults in two countries: Turkey $(n=1588)$ and Greece $(n=602)$. The interviews took place during September and October 2015 in Turkey, and June and July 2016 in Greece. Proportionate stratified sampling procedure was employed with strata based on age, city and socioeconomic status groups (SES). The size of the sample in each stratum is proportionally allocated based on the Turkish Statistical Institute (TUIK) and Hellenic Statistical Authority national data. ${ }^{1}$ The interviews were conducted across 16 cities and their municipalities in Turkey and six cities and their counties in Greece. The interviewees were randomly selected via a probability procedure based on predefined quotas. Participants were parts of national panels used by two professional polling companies that administrated the fieldwork. Only one respondent over 18 years old was selected from each household, and they were interviewed on a wide variety of topics related to political economy and foreign policy using Computer Assisted Personal Interviewing technique (CAPI) in their local language. ${ }^{2}$

To test the effect of the target country's political regime and cultural proximity with home on individual preferences on trade liberalization, I implemented two survey experiments. These experiments shared a scenario suggesting strengthening trade relations with a hypothetical country by signing a FTA. For the experimental part, the treatments are randomized using quotas on preset strata. Appendix

\footnotetext{
1 Relevant information on demographic and socioeconomic statistics of Turkey and Greece can be found at http://www.turkstat.gov.tr/Start.do and www.statistics.gr, respectively.

2 The complete text of the survey instrument is available from the authors.
}

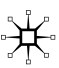


Table A1a and A1b report the demographic breakdown and distribution of covariates for both control and treatment groups and the target estimates.

To assess the effect of democracy as a trade partner attribute, in the first experiment, I manipulated the regime type of the partner country by providing respondents with the information that it is either a democracy or an authoritarian regime. Gauging the effect of cultural proximity, on the other hand, is more challenging as the term 'culture' may encompass a large array of measures depending on how the term is conceptualized. In studies that investigate the role of culture to explain bilateral trade flows, linguistic commonality (Melitz 2008), ethnic distance (Gokmen 2017) or even Eurovision song contest scores (Felbermayr and Toubal 2010) are used as a proxy of cultural distance. Because this study is interested in assessing the independent effect of respondent's identification of cultural identity of the home country, in the second experiment, respondents are first queried on the cultural group they believe their country belongs to along the salient ideational discourses and narratives in the donor's political culture. Reflecting the presence of a perpetual cultural clash in both countries, for Turkish subjects, the choices were Europe or the Middle East (e.g., Mardin 2006), while for Greeks, the choices were Western European or Eastern Orthodox (e.g., Roudometof 1999, 2002). Accordingly, 38\% of Turkish respondents defined Turkey as a European country, and $53.4 \%$ defined it as Middle Eastern. In Greece, on the other hand, $47.4 \%$ identified their country as Western European and $29.9 \%$ as an Eastern Orthodox country.

Next, in the vignette, the geographical location of the target country is varied along these lines with an important modification in the Greek survey. For the Greek subjects, a direct manipulation of groups with the Western European treatment was left off to avoid confusion for one-fourth of the sample, who would be assigned the Western European and authoritarian regime treatment, which would not correspond to reality. Though this choice renders it impossible to further investigate Greek respondents' attitudes with respect to Western European trade partners, it enhances the internal validity of the survey experiment. Consequently, the four treatment groups are established along the democracy/authoritarian and European/ Middle Eastern axes in the Turkish survey, and along the democracy/authoritarian and Eastern Orthodox/no cultural information axes in the Greek survey.

The wording of the vignette was as follows:

Economic relations with the European/Middle Eastern (in Turkey) or Eastern Orthodox/no cultural information (in Greece) Country C ruled by a (democratic/ authoritarian) regime have been improving at a rapid pace in the last several years. Businessmen in both countries are urging policymakers to sign a bilateral free trade agreement in order to further relations. If the countries sign such an agreement, Turkey/Greece will bilaterally remove trade barriers and allow imports to enter the home market without being subjected to tariffs.

Should Turkey/Greece sign a free trade agreement with country C? 1=Disagree strongly to 5=Agree strongly.

Although selecting a hypothetical country presents a challenge in drawing conclusions on policy implications, it eliminated the risk of the respondents assigning particular attributes to the target country for which we cannot control. Isolation of treatment effects was particularly important for the second experiment, as the 
cultural proximity between countries is closely correlated with distance, and hence predispositions of respondents about the countries in their close environs could have influenced their preferences and presented potential confounding problems. Minimizing specificities and contextual differences across samples also enabled a more direct cross-national comparison.

To determine which subgroups are more pro-trade with particular partners and why, I utilize three moderator variables, namely, respondents' postmaterialist orientation, general support for free trade agreements and a battery of questions on interpersonal and transnational trust levels, all asked post-treatment. To identify personal value orientation with respect to democracy, I used Inglehart's four-item postmaterialism index (1971). Accordingly, those who select postmaterialist goals, namely giving people a greater say in important political decisions and protecting freedom of speech, are considered normatively more committed to democracy and more likely to have developed ideational affiliation with other democracies.

Based on the discussion of the relevant literature, I incorporated several control variables in the statistical analyses. According to the Heckscher-Ohlin theorem, skilled labor in capital-rich, developed countries and unskilled labor in labor-rich, underdeveloped or developing countries will benefit from trade liberalization and tend to support economic openness. Unskilled labor in developed countries and skilled labor in underdeveloped and developing countries, conversely, will face economic costs and thus oppose such attempts. In line with the expectation of the factor endowment model, I control for respondents' skill levels by measures on occupation and education.

Age and gender are controlled, with the expectation that the younger populace holds more cosmopolitan views and is more open to supranational influences, whereas the older, and women, two groups with greater economic vulnerability, are likely to be much more risk-averse and protectionist (e.g., Tucker et al. 2002). Because political ideology cues citizens to form preferences on trade liberalizations (e.g., Urbatsch 2013), self-reported ideological orientation is controlled for with a $10=$ point scale. Appendix Table A2 reports the detailed variable description and summary statistics.

\section{Results and discussion}

At the individual level, the ordered logistic regression results, presented in Table 1, demonstrate strong causal effect of a democratic political regime as a partner attribute in eliciting support for trade liberalization. The results are robust also when I measure the treatment effects in isolation (Model-1) or in the presence of standard demographic variables (Model-2). Respondents in both countries are substantially and statistically more supportive of signing a FTA with a democracy than an autocracy. Calculation of marginal effects establishes that the democracy treatment increases the predicted probability of choosing 4 (agree) or 5 (agree strongly) on signing a FTA by 6.6 percent in Turkey and 14 percent in Greece, and decreases the probability of choosing 1 (disagree strongly) or 2 (disagree) by 4.9 and 21 percent in Turkey and Greece, respectively. Of the covariates in Model-2, in both samples, 
Table 1 Treatment effects-ordered logit estimates

\begin{tabular}{|c|c|c|c|c|}
\hline \multirow[t]{2}{*}{ Variables } & \multicolumn{2}{|l|}{ Turkey } & \multicolumn{2}{|l|}{ Greece } \\
\hline & (1) & (2) & (1) & (2) \\
\hline Democracy treatment & $\begin{array}{l}0.27 * * * \\
(0.09)\end{array}$ & $\begin{array}{l}0.34 * * * \\
(0.11)\end{array}$ & $\begin{array}{l}0.86^{* * * * *} \\
(0.15)\end{array}$ & $\begin{array}{l}1.21 \text { **** } \\
(0.19)\end{array}$ \\
\hline Cultural treatment & $\begin{array}{r}-0.10 \\
(0.09)\end{array}$ & $\begin{array}{r}-0.12 \\
(0.11)\end{array}$ & $\begin{array}{r}-0.02 \\
(0.15)\end{array}$ & $\begin{array}{r}-0.07 \\
(0.19)\end{array}$ \\
\hline Age & & $\begin{array}{c}0.00 \\
(0.00)\end{array}$ & & $\begin{array}{c}0.00 \\
(0.01)\end{array}$ \\
\hline Gender & & $\begin{array}{c}0.12 \\
(0.13)\end{array}$ & & $\begin{array}{r}-0.04 \\
(0.19)\end{array}$ \\
\hline Education & & $\begin{array}{c}0.03 \\
(0.03)\end{array}$ & & $\begin{array}{c}0.02 \\
(0.06)\end{array}$ \\
\hline Postmaterialism & & $\begin{array}{l}0.27 * * \\
(0.13)\end{array}$ & & $\begin{array}{r}-0.11 \\
(0.23)\end{array}$ \\
\hline Interpersonal trust & & $\begin{array}{r}-0.04 \\
(0.17)\end{array}$ & & $\begin{array}{r}-0.02 \\
(0.20)\end{array}$ \\
\hline Free trade & & $\begin{array}{l}0.53 * * * * \\
(0.12)\end{array}$ & & $\begin{array}{l}1.23 \text { **** } \\
(0.20)\end{array}$ \\
\hline Ideology & & $\begin{array}{l}0.07 * * * * \\
(0.02)\end{array}$ & & $\begin{array}{c}0.07 \\
(0.05)\end{array}$ \\
\hline Labor & & $\begin{array}{r}-0.14 \\
(0.23)\end{array}$ & & $\begin{array}{r}-0.08 \\
(0.81)\end{array}$ \\
\hline Employees & & $\begin{array}{r}-0.31 \\
(0.29)\end{array}$ & & $\begin{array}{c}0.30 \\
(0.80)\end{array}$ \\
\hline Employers & & $\begin{array}{r}-0.01 \\
(0.26)\end{array}$ & & $\begin{array}{c}0.73 \\
(0.81)\end{array}$ \\
\hline Students/housewives/retired/ & & $\begin{array}{r}-0.15 \\
(0.23)\end{array}$ & & $\begin{array}{r}-0.14 \\
(0.96)\end{array}$ \\
\hline Observations & 1588 & 1078 & 600 & 405 \\
\hline
\end{tabular}

Ordered logit estimates with standard errors in parentheses. Cut-points are not reported $* * * * p<0.001, * * * p<0.01, * * p<0.05, * p<0.1$

expectedly, those who hold favorable attitudes toward international trade are more supportive of signing free trade agreements. Only in Turkey, right-wing voters and postmaterialists are positively inclined to support trade liberalization.

The $t$ test results presented in Tables 2 and 3 reaffirm the previous findings and show that the effect of the political regime remains significant and consistent across the groups conditioned by the cultural treatment. The results reveal two further points: First, support for preferential trade liberalization is considerably lower in Greece than in Turkey. This response is most likely conditioned by the prevailing economic conditions in the country, as in times of economic crises, public opinion tends to turn against economic integration and neoliberal economic policies 
Table 2 Experimental treatment effects

\begin{tabular}{llll}
\hline & \multicolumn{2}{l}{ Turkey } & \\
\cline { 2 - 3 } & Partner is European & Partner is Middle Eastern & Effect of culture \\
\hline Partner is democracy & $3.27(N=412)$ & $3.37(N=393)$ & 0.10 \\
Partner is authoritarian & $3.16(N=393)$ & $3.18(N=390)$ & 0.02 \\
Effect of democracy & $0.11^{*}$ & $0.19 * * *$ & \multirow{2}{*}{ Effect of culture } \\
\hline & Greece & Partner is Eastern orthodox & -0.02 \\
\cline { 2 - 4 } & No treatment & $2.88(N=148)$ & 0.0 \\
\hline Partner is democracy & $2.86(N=147)$ & $2.37(N=152)$ & \\
Partner is authoritarian & $2.37(N=153)$ & $0.51 * * * *$ & \\
Effect of democracy & $0.49 * *$ &
\end{tabular}

The mean score denotes the average view of respondents on the effect of signing FTA with country C on a five points scale. The $\mathrm{t}$ statistic is obtained from a $t$ test comparing the treatment groups

Table 3 Effect of culture, controlling cultural affinity and trust

\begin{tabular}{lll}
\hline & Turkey & \\
\cline { 2 - 3 } & Turkey belongs to Europe & Turkey belongs to Middle East \\
\hline Partner is Middle Eastern & $3.38(269)$ & $3.22(425)$ \\
Partner is European & $3.33(323)$ & $3.10(407)$ \\
Effect of culture & -0.05 & $0.12 *$ \\
Partner is Middle Eastern & High trust to Islamic countries & High trust to the EU \\
Partner is European & $3.37(N=230)$ & $3.34(N=252)$ \\
Effect of culture & $3.28(N=211)$ & $3.25(N=241)$ \\
\hline & 0.09 & -0.09 \\
\hline Partner is Eastern orthodox & Greece & \\
\cline { 2 - 3 } & Greece belongs to Western Europe & Greece belongs to Eastern \\
Effect of culture & $2.91(N=53)$ & Europe \\
\hline & 0.02 & $2.50(75)$ \\
Effect of culture & $2.60(137)$ & $2.78(94)$ \\
No treatment & $2.53(130)$ & 0.28 \\
Lartner is Eastern orthodox & -0.07 & $\begin{array}{l}\text { Low trust to the EU } \\
2.57(N=255) \\
2.56(N=247) \\
-0.01\end{array}$ \\
\hline
\end{tabular}

The mean score denotes the average view of respondents on the effect of signing FTA with country C on a five points scale controlling respondent's identification of home country with a particular civilizational group and trust levels. The $t$ statistic is obtained from a $t$ test comparing the treatment groups

(e.g., Gabel 1998; Hellwig and Coffey 2011). Second, Greek respondents display greater responsiveness to the democracy treatment. Given the deeper roots of 
democratic consolidation in the Greek political culture as compared to Turkey, the higher degrees of sensitivity to the democracy treatment in Greece conform to our expectations.

The cultural location of the partner country, in contrast, does not condition respondents' opinions in preferential trade liberalization. Contradictory to Spilker et al.'s findings (2016), the null results persist when respondents' self-identification of their country with a particular culture is controlled for (Table 3). Yet, those who define Turkey as European, similar to those who define Greece as an Eastern Orthodox country, are no more likely to support trade liberalization agreements with countries from these civilizations. In Turkey, there is marginally greater support for signing a trade agreement with another Middle Eastern country by those who define Turkey as a Middle Eastern country, though the correlation is only weakly significant at the 0.1 level.

One may argue that respondents' identification of the home country with a particular group may be evoked by objective self-assessments rather than subjective positions or values with respect to the particular civilizational group. For instance, a Turkish respondent might classify Turkey as a Middle Eastern country even though they subjectively believe Turkey ought to belong to European civilization. Previous studies have proposed that cultural commonality may affect partner preferences via its effect on bilateral trust (e.g., Spilker et al. 2016). To address this mechanism, the survey instrument posed questions with regard to respondents' bilateral trust in a certain group of countries. The results establish that even after controlling for bilateral trust, cultural treatment fails to attain statistical significance in driving respondents' attitudes. Although those who expressed trust in Islamic countries are 0.09 points more supportive of preferential trade liberalization with a country in the Middle East, this difference does not attain any statistical significance. Those who expressed trust in the EU, conversely, are in fact less supportive of preferential trade agreements with countries in Europe than in the Middle East, though once again not statistically significantly so. Similarly, in the Greek sample, those who display distrust in the EU are no more likely to positively evaluate Eastern Orthodox trade partners.

Having established that respondents are more partial to partners with democratic regimes for preferential trade liberalization, I next estimate the differing effect of experimental treatment for three selected subgroups with the objective of assessing respondents' reasoning in choosing democratic trade partners.

Figures 1, 2 and 3 present the predicted margins of postmaterialism, support for international trade, and interpersonal trust on support for democratic and autocratic trade partners. Specifically, the figures plot the changes in the effect of regime treatment for the values of three binary moderator variables. The plotted estimates reveal that in the Turkish sample, postmaterialists are not significantly more supportive of signing a trade deal with a democracy. Namely, those who are normatively committed to democracy do not differentiate between democracies and autocracies. Instead, materialists largely induce the overall preference for democracy, as the democracy treatment exerts a highly significant effect for this group. The results also demonstrate that the democracy treatment exerts an effect only for free traders and 


\section{Predictive Margins of Post-materialism with 95\% Cls}

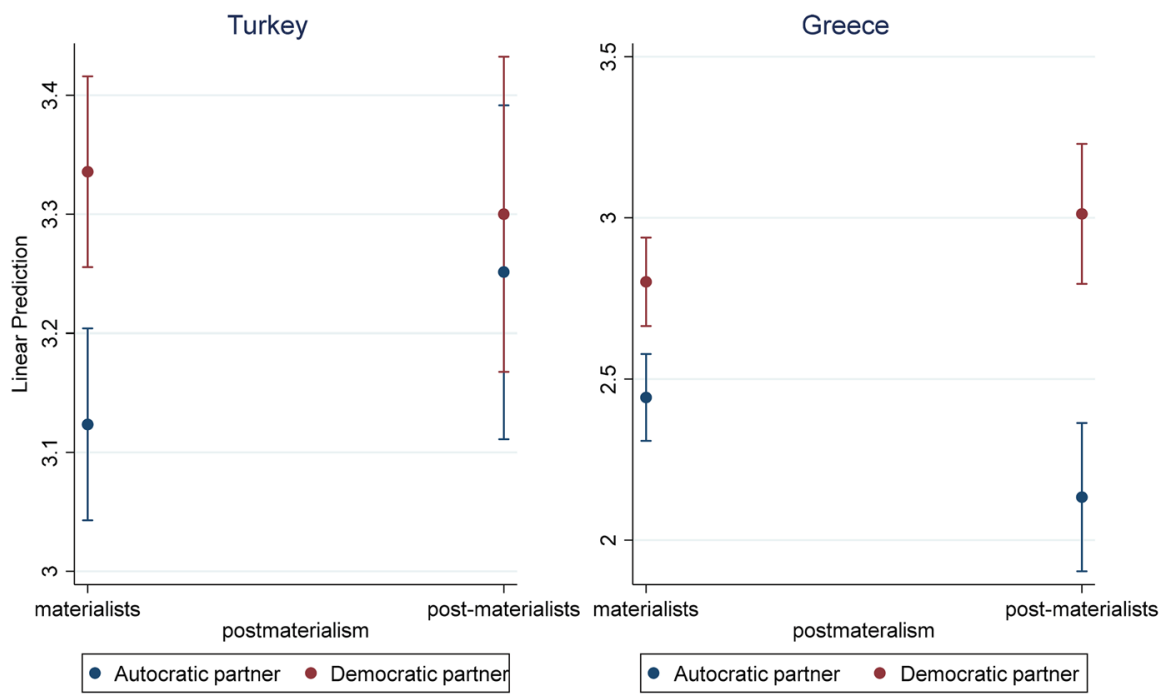

Fig. 1 Predictive margins of postmaterialism across regime treatment

Predictive Margins of Free trade support with $95 \% \mathrm{Cls}$
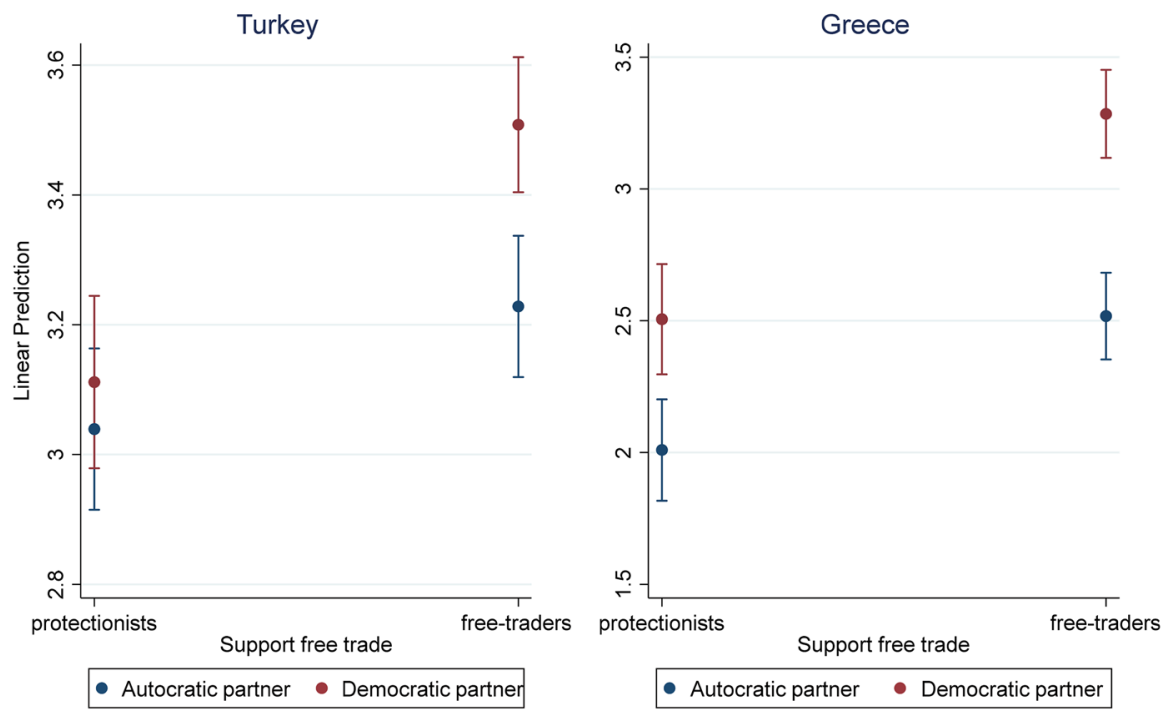

Fig. 2 Predictive margins of general trade attitudes across regime treatment

distrusting individuals, whereas protectionist and those with higher social trust do not differentiate between the regime type of their countries' trade partner. 


\section{Predictive Margins of Interpersonal trust with $95 \% \mathrm{Cls}$}
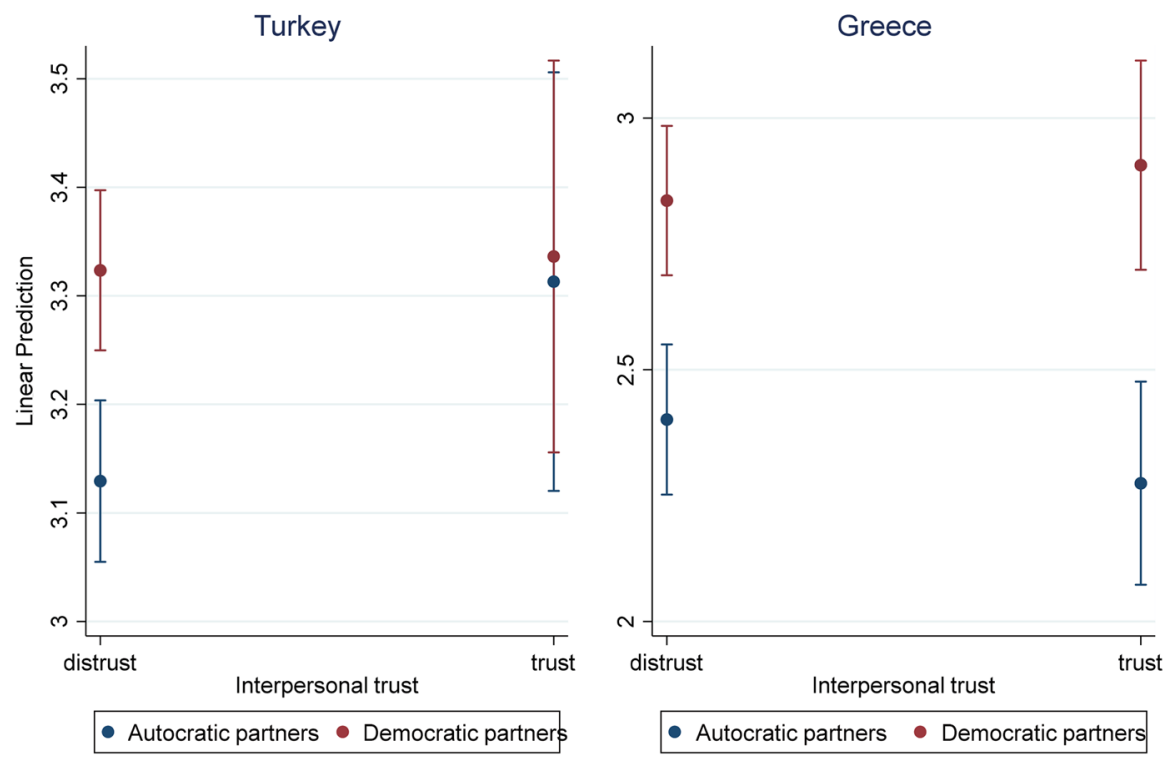

Fig. 3 Predictive margins of interpersonal trust across regime treatment

In the Greek sample, the democracy treatment attains high statistical significance irrespective of respondents' levels of postmaterialism, support for international trade or interpersonal trust. At the same time, the treatment exerts substantially greater effects on those who endorse postmaterialist values and support international trade. Because free traders may be inclined to support democratic trade partners for both functional and normative reasons, while protectionists would oppose democratic trade partners due to the fear of higher bilateral trade volumes and are willing to consider democratic partners due to normative affiliations, protectionists' endorsement of democratic trade partners indicates the presence of normative mechanisms in the Greek sample. We can draw a similar conclusion based on the higher sensitivity of postmaterialists to the treatment effects. Margins analyses illustrate that the predicted probability of supporting trade agreement with a democracy (choosing either agree or agree strongly options) is $37 \%$ for postmaterialists as opposed to $26 \%$ for materialists, and the probability of signing a trade deal with an autocracy is $9 \%$ for the former group as opposed to $16 \%$ for the latter. In other words, individuals who value democratic goals as a normative good are not only significantly more likely to support trade liberalization with other democratic countries, but also substantially more inclined to prefer democratic trade partners compared to those who endorse materialist values.

To further investigate how the regime treatment affects other subpopulation groups in Turkey and Greece, in Appendix Table A3, I measure treatment effects for the control variables in Table 1. In line with the previous results, in Greece, the treatment effects are homogenously distributed across different population groups. 
The effect sizes are weaker for Turkey and less consistent compared to Greece. In the Turkish sample, those who are younger, male, less educated, ideologically center and right-wing oriented are significantly more sensitive to the democracy treatment.

In conjunction, these results show that only specific groups of respondents in Turkey, in particular those who would be more appreciative of the material benefits trading with democracies accrue, are significantly more supportive of trade liberalization with democratic partners over authoritarian ones. In the Greek sample, conversely, the treatment exerts statistical significance for different subpopulation groups and particularly strong effects for those with closer affinity toward democratic values. These results tentatively point to the presence of functional reasons rather than normative ones stimulating the Turkish preferences, whereas both normative and functional mechanisms are operative in shaping Greek attitudes.

\section{Conclusion}

This paper investigated the origins of opinions on preferential trade liberalization and examined if citizens are more likely to develop favorable trade attitudes toward other democracies or countries that they believe belong to the same cultural groups. I based the empirical analysis on two survey experiments on nationally representative samples drawn from Turkey and Greece, two emerging markets with relatively open economies though vastly divergent in terms of salient cultural identities and degrees of democratic consolidation. Experimental manipulation of the regime type and the cultural group of the partner country revealed two findings. One, respondents who identify their country with a particular cultural group were no more likely to support trade liberalization with fellow countries within the same circle. Two, in both samples, respondents displayed a clear preference for signing trade agreements with democratic partners over autocracies.

To assess if functional or normative dynamics influence the preference for democratic partners, I utilized three proxies: Inglehart's postmaterialism index, general support for international trade, and interpersonal trust. My assessment maintained that in the Turkish sample, only materialists, free traders and those with low levels of social trust displayed statistically significant preference for democratic trade partners. Those who are normatively committed to democracy, protectionists, or those with high social trust, in contrast, were no more supportive of signing a FTA with a democracy over an autocracy. This finding suggested that it is the functional advantages of democratic trade partners that diminish risk associated with doing business abroad and consequently enhance gains from trade are instrumental in conditioning Turkish respondents' preferences. As such, there was no indication of a normative affinity in driving Turkish preferential trade attitudes. In Greece, conversely, despite varying in degree, the democracy treatment exerted a significant effect for all subpopulation groups. In particular, unlike the Turkish sample, those who are committed to democratic values are found to be more sensitive to the democracy treatment. Another notable finding was that protectionists, who were otherwise more likely to be financially hurt from trading with democracies, were supportive of trading with 
democracies. In conjunction, these results pointed to the joint presence of normative and functional reasons operative in the Greek sample.

These survey experiments offer high internal validity, yet one should be cautious while extrapolating these findings to other similarly developed countries. One, Turkey and Greece are unique cases with deeply rooted cultural cleavages. Though the presence of competing cultural groups embedded in these countries enables a more comprehensive test of cultural effects, it also runs the risk of diluting the overall effect of the cultural treatment. Moreover, the measurement of cultural proximity is relatively more subjective than the regime type and may introduce certain biases. For instance, in our experiment, information on the partner country's geographical identity might have primed respondents on other uncontrolled predispositions about the partner country characteristics, such as its geographical distance or political alliance rather than its cultural effects as intended. Thus, future studies should explore the cultural effects on trade attitudes by developing diverse methods to define and gauge cultural proximity for a wider range of countries with different civilizational identities.

Another factor that merits attention is the special role the EU plays in the trade policies of these countries. Though Turkey has sovereign control over the choice of trade partners, Greece has conceded to the European common trade policy; it has deferred the authority to conclude trade agreements to the Commission. At the same time, given the democratic deficit critiques surrounding the EU integration and the rise of new protectionism in the post-COVID-19 era, there are ample reasons to study public attitudes on trade in the EU. Thus far, studies have analyzed trade attitudes in major EU powers (e.g., Kaltenthaler et al. 2004; Steiner 2018), largely neglecting smaller members. However, an EU trade agreement concluded with foreign countries needs the unanimous support of all 28 member states and is occasionally put to referendums in some member states (e.g., the Dutch no vote to an association agreement with Ukraine in 2016).

Global economic integration today has become a salient issue area for public opinion, in both the developed and developing worlds. Hence, we need more indepth and diverse accounts to illuminate how public opinion is formed. We also need finer theory building that seeks to investigate the sources of conflicting public opinions on preferential trade liberalization depending on the identity of the partner country. Such investigations would be also valuable to policymakers, as they could utilize such information to either select their trade partners accordingly or frame trade liberalization with the proposed partners in a way that elicits greater electorate support. The findings of this research indicate that in an age of growing public discomfort with free trade, a preferential trade agreement with a democratic country is less likely to receive less resistance if the government underlines the regime type of its partners while garnering support from its voters. However, the political regime is but one factor that affects public sensitivity in choosing free trade partners. Further analyses to determine the other factors are warranted.

Funding This Project is fully funded by Bogazici University, Istanbul, with the Grant code 15N02SUP1. 


\section{References}

Baker, A. 2003. Why is trade reform so popular in Latin America. World Politics 55 (3): 423-455.

Barro, R.J. 1999. Determinants of democracy. Journal of Political Economy 107 (S6): S158-S183.

Beaulieu, E., R.A. Yatawara, and W.G. Wang. 2005. Who supports free trade in Latin America? World Economy 28 (7): 941-958.

Bliss, H., and B. Russett. 1998. Democratic trading partners: the liberal connection, 1962-1989. The Journal of Politics 60 (04): 1126-1147.

Bush, S.S., and L. Prather. 2020. Foreign meddling and mass attitudes toward international economic engagement. International Organization 74: 584-609.

Dixon, W.J., and B.E. Moon. 1993. Political similarity and American foreign trade patterns. Political Research Quarterly 46 (1): 5-25.

Dow, D., and A. Karunaratna. 2006. Developing a multidimensional instrument to measure psychic distance stimuli. Journal of International Business Studies 37 (5): 578-602.

Doyle, M.W. 2005. Three pillars of the liberal peace. American Political Science Review 99 (03): 463-466.

Eckstein, H. 2000. A culturalist theory of political change. In Culture and politics, ed. L. Crothers, and C. Lockhart, 307-324. Springer.

Ehrlich, S.D. 2009. Constituency size and support for trade liberalization: An analysis of foreign economic policy preferences in congress. Foreign Policy Analysis 5 (3): 215-232.

Felbermayr, G.J., and F. Toubal. 2010. Cultural proximity and trade. European Economic Review 54 (2): 279-293.

Gabel, M.J. 1998. Economic integration and mass politics: Market liberalization and public attitudes in the European Union. American Journal of Political Science 42 (3): 936-953.

Gokmen, G. 2017. Clash of civilizations and the impact of cultural differences on trade. Journal of Development Economics 127: 449-458.

Granzin, K.L., J.D. Brazell, and J.J. Painter. 1997. An examination of influences leading to Americans' endorsement of the policy of free trade. Journal of Public Policy \& Marketing 16: 93-109.

Hellwig, T., and E. Coffey. 2011. Public opinion, party messages, and responsibility for the financial crisis in Britain. Electoral Studies 30 (3): 417-426.

Herrmann, R.K., P.E. Tetlock, and M.N. Diascro. 2001. How Americans think about trade: Reconciling conflicts among money, power, and principles. International Studies Quarterly 45 (2): 191-218.

Hicks, R., H.V. Milner, and D. Tingley. 2014. Trade policy, economic interests, and party politics in a developing country: The political economy of CAFTA-DR. International Studies Quarterly 58 (1): $106-117$.

Inglehart, R. 1971. The silent revolution in Europe: Intergenerational change in post-industrial societies. American Political Science Review 65 (04): 991-1017.

Jensen, N.M., Lindstädt, R. 2013. Globalization with whom: Context-dependent foreign direct investment preferences. Working paper.

Jungherr, A., et al. 2018. Context-driven attitude formation: The difference between supporting free trade in the abstract and supporting specific trade agreements. Review of International Political Economy 25 (2): 215-242.

Kaltenthaler, K., and W.J. Miller. 2013. Social psychology and public support for trade liberalization. International Studies Quarterly 57 (4): 784-790.

Kaltenthaler, K.C., R.D. Gelleny, and S.J. Ceccoli. 2004. Explaining citizen support for trade liberalization. International Studies Quarterly 48 (4): 829-851.

Katzenstein, P.J. 2009. Civilizations in world politics: Plural and pluralist perspectives. Abingdon: Routledge.

Kiratli, O.S. 2020. On the question of generosity: Who supports foreign aid to whom?-Lessons from Turkey and Greece. International Journal of Public Opinion Research 32 (1): 176-188.

Kono, D.Y. 2008. Does public opinion affect trade policy? Business and Politics 10 (2): 1-19.

Kunczik, M. 2016. Images of nations and international public relations. Abingdon: Routledge.

Levchenko, A.A. 2007. Institutional quality and international trade. The Review of Economic Studies 74 (3): 791-819.

Lipson, C. 2005. Reliable partners: How democracies have made a separate peace. Princeton: Princeton University Press. 
Mansfield, E.D., H.V. Milner, and B.P. Rosendorff. 2000. Free to trade: Democracies, autocracies, and international trade. American Political Science Review 94 (02): 305-321.

Mansfield, E.D., H.V. Milner, and B.P. Rosendorff. 2002. Why democracies cooperate more: Electoral control and international trade agreements. International Organization 56 (03): 477-513.

Mardin, Ş. 2006. Religion, society, and modernity in Turkey. Syracuse: Syracuse University Press.

Mayda, A.M., and D. Rodrik. 2005. Why are some people (and countries) more protectionist than others? European Economic Review 49 (6): 1393-1430.

Melitz, J. 2008. Language and foreign trade. European Economic Review 52 (4): 667-699.

Naoi, M. 2009. Shopping for protection: The politics of choosing trade instruments in a partially legalized world. International Studies Quarterly 53 (2): 421-444.

Naoi, M., and S. Urata. 2013. Free trade agreements and domestic politics: The case of the Trans-Pacific Partnership Agreement. Asian Economic Policy Review 8 (2): 326-349.

Nguyen, Q., and T. Bernauer. 2019. 'Does social trust affect public support for international trade? Insights from an experiment in Vietnam. Political Studies 67 (2): 440-458.

North, D.C. 1984. Transaction costs, institutions, and economic history. Zeitschrift für die Gesamte Staatswissenschaft/Journal of institutional and Theoretical Economics H. 1: 7-17.

Polachek, S.W. 1980. Conflict and trade. Journal of Conflict Resolution 24 (1): 55-78.

Putnam, R. 1993. 'The prosperous community: Social capital and public life', The American prospect, 13(Spring), Vol. 4. Available online: http://www.prospect.org/print/vol/13. Accessed 7 April 2003.

Rankin, D.M. 2001. Identities, interests, and imports. Political Behavior 23 (4): 351-376.

Rauch, J.E. 1999. Networks versus markets in international trade. Journal of International Economics 48 (1): 7-35.

Rodrik, D. 1995. Political economy of trade policy. Handbook of International Economics 3: 1457-1494.

Rodrik, D. 2000. Institutions for high-quality growth: What they are and how to acquire them. National bureau of economic research. http://www.nber.org/papers/w7540. Accessed 6 Mar 2017.

Roudometof, V. 1999. Nationalism, globalization, Eastern Orthodoxy: Unthinking'theClash of civilizations' in southeastern Europe. European Journal of Social Theory 2 (2): 233-247.

Roudometof, V. 2002. Collective memory, national identity, and ethnic conflict: Greece, Bulgaria, and the Macedonian question. Santa Barbara: Greenwood Publishing Group.

Russett, B. 1994. Grasping the democratic peace: Principles for a post-Cold War world. Princeton: Princeton University Press.

Scheve, K.F., and M.J. Slaughter. 2001. Labor market competition and individual preferences over immigration policy. Review of Economics and Statistics 83 (1): 133-145.

Spilker, G., T. Bernauer, and V. Umaña. 2016. Selecting partner countries for preferential trade agreements: Experimental evidence from Costa Rica, Nicaragua, and Vietnam. International Studies Quarterly 60 (4): 706-718.

Steiner, N.D. 2018. Attitudes towards the transatlantic trade and investment partnership in the European Union: The treaty partner heuristic and issue attention. European Union Politics 19 (2): 255-277.

Tucker, J.A., A.C. Pacek, and A.J. Berinsky. 2002. Transitional winners and losers: Attitudes toward EU membership in post-communist countries. American Journal of Political Science 46 (3): 557-571.

Urbatsch, R. 2013. A referendum on trade theory: Voting on free trade in Costa Rica. International Organization 67 (01): 197-214.

Uslaner, E.M. 1998. Trade winds: NAFTA and the rational public. Political Behavior 20 (4): 341-360.

Uslaner, E.M. 2003. Trust, democracy and governance: Can government policies influence generalized trust? In Generating Social Capital, ed. M. Hooghe, and D. Stolle. New York: Palgrave Macmillan. https://doi.org/10.1057/9781403979544_9.

Whiteley, P.F. 2000. Economic growth and social capital. Political studies 48 (3): 443-466.

Yu, M. 2007. Trade globalization and political liberalization: a gravity approach. SSRN 906280. http:// papers.ssrn.com/sol3/papers.cfm?abstract_id=906280. Accessed 20 Nov 2016.

Publisher's Note Springer Nature remains neutral with regard to jurisdictional claims in published maps and institutional affiliations.

Dr. Osman Sabri Kiratli is an associate professor in the International Trade Department at Bogaziçi University, Istanbul. His research areas include public opinion dynamics on cooperation and conflict, European integration, EU Foreign Policy and International Political Economy. 